\title{
Research
}

\section{Cost-effectiveness of point-of-care C-reactive protein testing to inform antibiotic prescribing decisions}

\begin{abstract}
Background

Point-of-care C-reactive protein (POCCRP) is a biomarker of inflammation that offers clinicians a rapid POC test to guide antibiotic prescribing decisions for acute cough and lower respiratory tract infections (LRTI). However, evidence that POCCRP is cost-effective is limited, particularly outside experimental settings.
\end{abstract}

Aim

To assess the cost-effectiveness of POCCRP as a diagnostic tool for acute cough and LRTI from the perspective of the health service.

\section{Design and setting}

Observational study of the presentation, management, and outcomes of patients with acute cough and LRTI in primary care settings in Norway and Sweden.

\section{Method}

Using hierarchical regression, data were analysed in terms of the effect on antibiotic use, cost, and patient outcomes (symptom severity after 7 and 14 days, time to recovery, and EQ-5D), while controlling for patient characteristics Iself-reported symptom severity, comorbidities, and health-related quality of life) at first attendance.

\section{Results}

POCCRP testing is associated with nonsignificant positive reductions in antibiotic prescribing $(P=0.078)$ and increased cost $(P=0.092)$. Despite the uncertainty, POCCRP testing is also associated with a cost per quality-adjusted life year (QALY) gain of $€ 9391$ At a willingness-to-pay threshold of $€ 30000$ per QALY gained, there is a $70 \%$ probability of CRP being cost-effective.

\section{Conclusion}

POCCRP testing is likely to provide a costeffective diagnostic intervention both in terms of reducing antibiotic prescribing and in terms of QALYs gained.

\section{Keywords}

antibiotics; cost-effectiveness; $\mathrm{C}$-reactive protein; primary health care; respiratory tract infections.

\section{INTRODUCTION}

A major challenge in managing patients with acute cough and lower respiratory tract infections (LRTI) is determining which patients will benefit from antibiotic treatment. It is often not feasible for clinicians to order microbiological and/or other investigations for all patients with symptoms of acute respiratory infections. Instead, clinicians generally rely on the patient's medical history and a basic physical examination. ${ }^{1}$ However, clinical assessment alone has poor predictive value. ${ }^{2-3}$ Consequently, antibiotics are often prescribed to those who are unlikely to benefit, contributing to the development of antimicrobial resistance..$^{4-5}$

A rapid test, point-of-care C-reactive protein (POCCRP) is widely used in Scandinavia to guide antibiotic management for acute cough and LRTI. ${ }^{6-7}$ Near-patient testing provides results in minutes and so guides antibiotic treatment decisions at the initial consultation. Although CRP level in patients with LRTI appear to strongly influence the likelihood of antibiotic prescribing, ${ }^{7}$ there remains mixed evidence about the diagnostic value of CRP in distinguishing bacterial from

R Oppong. BA, MSc, research fellow in health economics; J Coast, BA(Econ), MSc, PhD, professor of health economics, Health Economics Unit, School of Health and Population Sciences, University of Birmingham, Birmingham. M Jit, BSc, PhD, MPH, mathematical modeller and health economist, Modelling and Economics Unit, Public Health England, London. RD Smith, $B A, M S c, P h D$, professor of health system economics, Faculty of Public Health and Policy. London School of Hygiene and Tropical Medicine, London. CC Butler, BA, DCH, FRCGP, CCH, MD, Hon FFPH, professor of primary care medicine, Institute of Primary Care and Public Health, Cardiff University, Neuadd Meirionnydd, Cardiff. H Melbye MD PhD professor General Practice Research Unit, Department of Community Medicine, University of Tromso, Norway. viral infection (aetiology), and its prognostic value in indicating potential benefit from antibiotics. ${ }^{9-14}$ More evidence is needed about whether CRP is an effective diagnostic and prognostic tool in primary care.

The impact of POCCRP on antibiotic prescribing and patient outcomes has been assessed in clinical settings, showing that antibiotic prescribing in patients managed with POCCRP testing was lower than the control group, ${ }^{6}$ and that POCCRP did not compromise patient recovery. However, the study did not consider multiple outcomes and was limited to one country (the Netherlands); it is unclear whether results are generalisable to other high income countries

The aims of the work reported here were: first, to evaluate the impact of POCCRP testing in two European countries (Sweden and Norwayl on antibiotic prescribing; secondly, to confirm that it did not compromise patient recovery; and thirdly to assess the cost-effectiveness of the test for diagnosing LRTI from a health service perspective. Each is important in the essential purpose of POCCRP, to reduce antimicrobial resistance through improving antibiotic prescribing decisions.
S Mölstad, MD, PhD, professor, Department of Clinical Sciences in Malmö Family Medicine, Lund University, Sweden.

\section{Address for correspondence}

Raymond Oppong, Health Economics Unit, Schoo of Health and Population Sciences, Public Health Building, University of Birmingham, Birmingham, B15 2TT.

E-mail: r.a.opponglabham.ac.uk

Submitted: 19 December 2012; Editor's response: 19 February 2013; final acceptance: 11 March 2013

British Journal of General Practice

This is the full-length article (published online 1 Jul 2013) of an abridged version published in print. Cite this article as: Br J Gen Pract 2013 DOI: 10.3399/bjgp13X669185 


\section{How this fits in}

This study is the first to assess the costeffectiveness of point of care $\mathrm{C}$-reactive protein (POCCRP) in a pragmatic clinical setting using an observational design. The results of this study indicate that POCCRP is a cost-effective tool to aid antibiotic prescribing decisions for acute cough and lower respiratory tract infections.

\section{METHOD}

\section{Patients and settings}

This analysis was conducted as part of the Genomics to combat Resistance against Antibiotics in Community-acquired LRTI in Europe (GRACE) observational study, conducted in 14 primary care networks in 13 countries. This study recruited consenting patients aged $\geq 18$ years presenting to their GP for the first time with an acute or worsened cough as the main or dominant symptom for up to 28 days, or who had a clinical presentation suggesting LRTI. Consecutive eligible patients were recruited, and followed-up for 28 days. Full details of study design and clinical outcomes are reported elsewhere. ${ }^{15}$ For this analysis, data were included from two countries (Sweden and Norway) where primary care clinicians use POCCRP testing routinely in treating LRTI.

\section{Data collection}

Resource use. Healthcare resource use by patients was recorded from two sources. First, patients provided resourceuse information on a weekly basis in diary format, for each week over a 4-week period, including information about primary care clinic visits, nurse visits, and hospital admissions. Secondly, after the initial clinic visit, clinicians completed a case report form containing information about medical investigations, referrals, antibiotics, and other drug prescriptions.

Healthcare unit cost. Country-specific unit cost data were obtained from four sources: (i) national and international publications on costs; (ii) collaborators from the GRACE network; (iii) British health economists who had participated in studies in the countries; and (iv) health economists in the countries. Over-the-counter medication was classified into eight groups and costs generated for each group by estimating an average price from a list of drugs in that group. Costs in all countries were converted to Euros $(€)$ using purchasing power parities (PPPs) and 2007 prices. Full details are presented elsewhere. ${ }^{16}$ The cost of a POCCRP test was estimated to be $€ 6.20$ in Sweden and $€ 4.10$ in Norway.

Health outcomes. Health outcome data were collected from the following:

1. EQ-5D questionnaires: patients completed the EQ-5D questionnaire on the day of their initial primary care attendance, and then weekly until the end of the 4 weeks. EQ-5D comprises five dimensions (mobility, self-care, usual activities, pain/discomfort, and anxiety/ depression), each with three levels (no problems, some problems, and severe problems). ${ }^{17}$ The European harmonised value $\operatorname{set}^{18}$ was used to value the EQ-5D data.

2. Symptom diaries: Patients provided information about symptoms on a daily basis over a 4-week period using a validated measure presented in a diary. ${ }^{19}$ Symptoms included were cough, phlegm production, shortness of breath, wheezing, blocked nose, chest pain, fever, muscle ache, headache, disturbed sleep, feeling unwell, interference with normal activities, and interference with social activities. Each symptom was scored on a scale of $0-6$, where 0 indicated the symptom was absent and 6 indicated the highest level of severity. A composite score ranging between 0 and 100 was generated. ${ }^{15}$ Patients were deemed to have recovered when their composite score fell to 0 . Patients were also asked to indicate the day on which they felt well.

3. Case report forms. Clinicians completed case report forms at the initial clinic visit. Symptom information, comorbidities, and findings from chest auscultations were collected.

\section{Data analysis}

The effect of POCCRP testing on patient outcomes and antibiotic prescribing was investigated. First, patient characteristics at first clinic visit lage, length of illness prior to consulting, EQ-5D score, composite patientreported severity scores, comorbidities, findings from chest auscultations, and symptoms) between patients receiving and not receiving POCCRP were compared, to determine whether POCCRP tests were more likely to be given to a particular profile of patients. Secondly, the relationship between receiving POCCRP and outcomes was explored, using hierarchical regression to control for the effect of patient 
Table 1. Number of LRTI consultations where CRP tests are administered, by country

\begin{tabular}{lccc} 
& $\begin{array}{c}\text { CRP test } \\
\boldsymbol{n}(\%)\end{array}$ & $\begin{array}{c}\text { No CRP test } \\
\boldsymbol{n ( \% )}\end{array}$ & $\begin{array}{c}\text { Total } \\
\boldsymbol{N}(\%)\end{array}$ \\
\hline Sweden & $143(64.4)$ & $79(35.6)$ & $222(100)$ \\
\hline Norway & $138(93.2)$ & $10(6.8)$ & $148(100)$ \\
\hline All countries & $281(76.0)$ & $89(24.1)$ & $370(100)$ \\
\hline CRP $=$ C-reactive protein. & $L R T I=$ lower respiratory tract infection.
\end{tabular}

characteristics at first clinic visit (with explanatory variables stratified into patient and practice levels). Outcomes considered were antibiotic prescribing, EQ-5D scores on days 7 and 14 , composite severity scores on days 7 and 14 , days to recovery based on having no reported symptoms and patientreported days to recovery. Using the area under the curve approach, quality-adjusted life years (QALYS) were estimated from EQ-5D scores. QALYs provide a measure of benefit that combines quality and quantity of life; they are often used in healthcare decision making. ${ }^{20} \mathrm{~A}$ net monetary benefit value ${ }^{17}$ was estimated for each patient using the formula (threshold $x$ QALY) - total cost. This was included as a dependent variable in the model. The primary explanatory variable was whether or not POCCRP testing was administered. However, baseline EQ-5D scores, baseline composite severity score, patient comorbidities, symptoms at baseline, findings from chest auscultations, and country were also included as covariables.

Model estimates of the difference in healthcare costs and the probability of being prescribed antibiotics between patients receiving and not receiving POCCRP were compared. This was used to estimate cost-per-patient reduction in

\section{Table 2. Patient characteristics at first clinic visit}

\begin{tabular}{lccc} 
& $\begin{array}{c}\text { CRP test } \\
\text { administered, } \\
\text { mean (SD) }\end{array}$ & $\begin{array}{c}\text { No CRP test } \\
\text { administered, } \\
\text { mean (SD) }\end{array}$ & P-value \\
\hline Age, years & $51.73(15.14)$ & $52.30(14.37)$ & 0.75 \\
\hline Days of illness before consultation & $10.25(8.41)$ & $11.04(9.35)$ & 0.45 \\
\hline EQ-5D at baseline & $0.669(0.19)$ & $0.691(0.20)$ & 0.37 \\
\hline Severity score at baseline & $41.77(16.22)$ & $39.08(16.82)$ & 0.19 \\
\hline Comorbidity & $0.32(0.53)$ & $0.15(0.39)$ & $<0.01$ \\
\hline Chest findings & & & \\
Diminished breath sounds & $0.09(0.02)$ & $0.07(0.03)$ & 0.36 \\
Wheeze & $0.21(0.02)$ & $0.09(0.03)$ & 0.01 \\
Crackles & $0.19(0.02)$ & $0.15(0.04)$ & 0.40 \\
Rhonchi & $0.18(0.02)$ & $0.12(0.04)$ & 0.20 \\
\hline
\end{tabular}

$C R P=C$-reactive protein. $S D=$ standard deviation. prescribed antibiotics and cost per QALY gained. Incremental net benefits were also obtained. A cost-effectiveness acceptability curve (CEAC) showing the probability that POCCRP is cost-effective across a range of values that a decision maker is willing to pay for an additional QALY was constructed following the method of Hoch and colleagues. ${ }^{21-22}$ All analysis was carried out in Stata (version 12) and Microsoft ${ }^{\circledR}$ Excel $^{\circledast}$.

In Norway and Sweden, there is no explicit threshold at which an intervention is considered cost-effective. Thus, a threshold value of $€ 30000$ per QALY gained was assumed.

\section{RESULTS}

\section{Patient characteristics}

The study population included 370 patients of whom $32 \%$ were male and $68 \%$ female. Patients ranged in age from 18 to 86 years. All patients consulted with cough, 314 (84.9\%) with phlegm and 321 (86.8\%) felt generally unwell. There was a higher rate of CRP testing by clinicians in Norway (Table 1). Diaries were completed by all 370 patients that were included in this study.

\section{Association between patient}

\section{characteristics at first visit and CRP use}

Patients receiving POCCRP tests presented to their GP with more comorbidities than those not administered the test $(P<0.01)$. There was no significant difference in EQ-5D scores, and severity scores between the two groups at the initial clinic visit (Table 2).

\section{Resource use}

Having POCCRP was significantly associated with undergoing more medical investigations and fewer hospital admissions $(P<0.01)$. After controlling for patient characteristics, the POCCRP group was still associated with having more medical investigations and fewer hospital admissions ( $P=0.03)$. All other resource use items were not significantly associated with POCCRP at the 5\% significance level (Table 3).

\section{Costs}

Patients receiving POCCRP tests had greater mean healthcare costs compared to patients who did not, but this difference was not statistically significant either before adjustment or after using hierarchical regression to account for patient characteristics at first visit (Table 3).

\section{Patient outcomes}

Patients receiving POCCRP did not have 


\section{Table 3. Relationship between administration of CRP test patient outcomes and resource use}

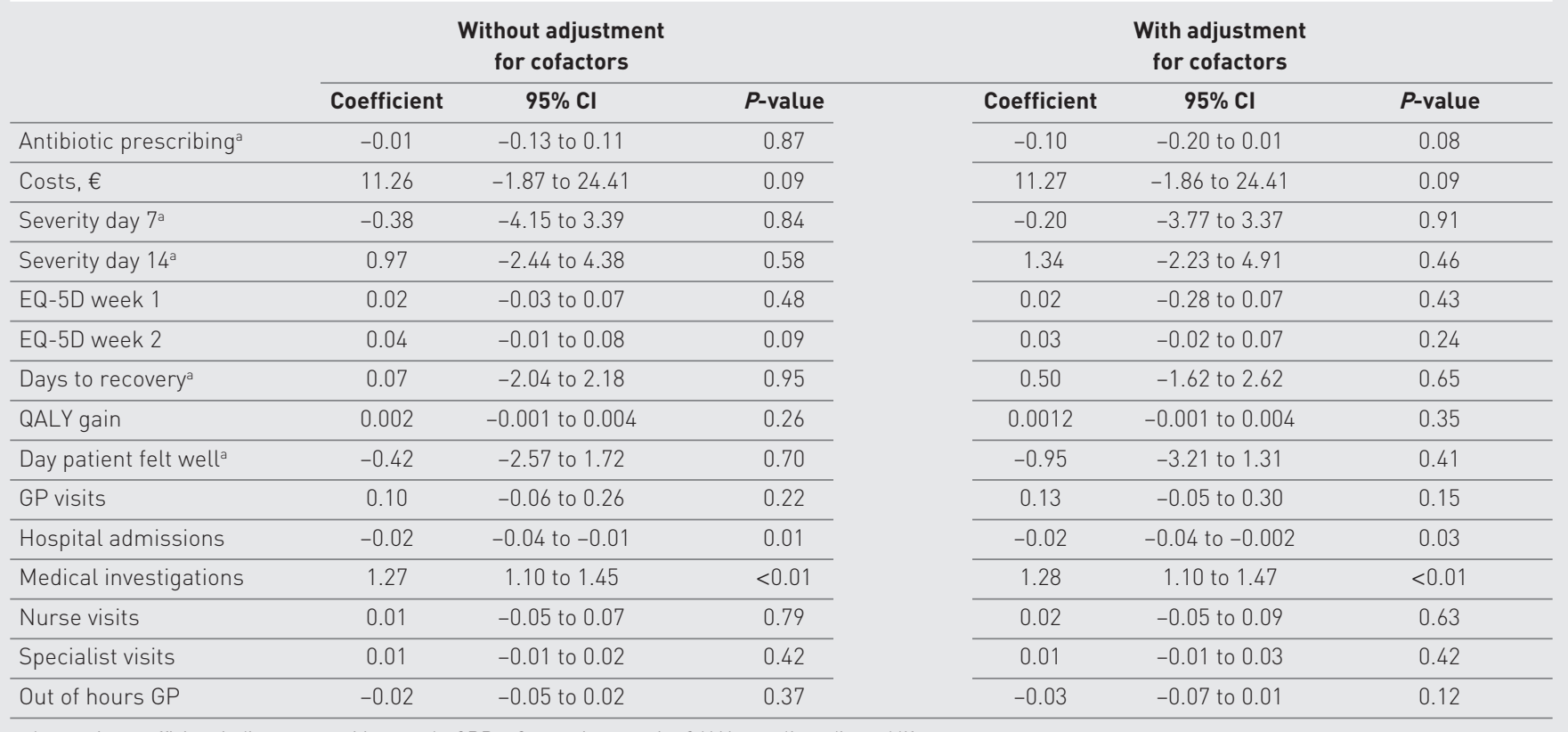

${ }^{a} A$ negative coefficient indicates a positive result. $C R P=C$-reactive protein. $Q A L Y=$ quality-adjusted life years.

significantly different measures of recovery or outcomes compared to patients not receiving this test (Table 3 )

\section{Antibiotic prescribing}

Antibiotic prescribing was lower in the POCCRP group but this relationship was not statistically significant at the 5\% level either before adjustment or after patient characteristics at first clinic visit were taken into account ( $P=0.08$; Table 3$)$.

\section{Cost-effectiveness}

Once patient characteristics at first clinic visit are accounted for, the regression model predicts that use of POCCRP increases healthcare costs by $€ 11.27$ $(P=0.09)$ and reduces the probability of antibiotic prescribing by $10 \%(P=0.08)$ per patient. This suggests that an additional cost per patient prescription avoided as a result of POCCRP is $€ 112.70$. POCCRP is also associated with a cost per QALY

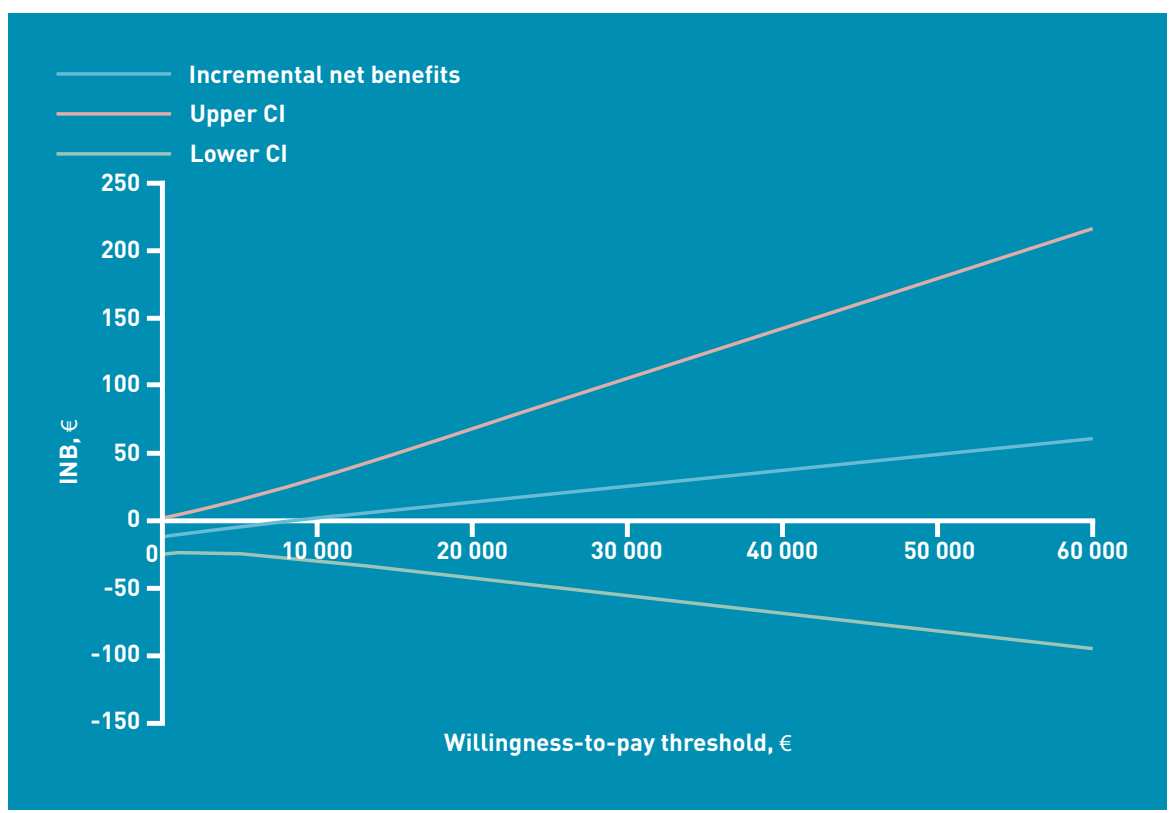




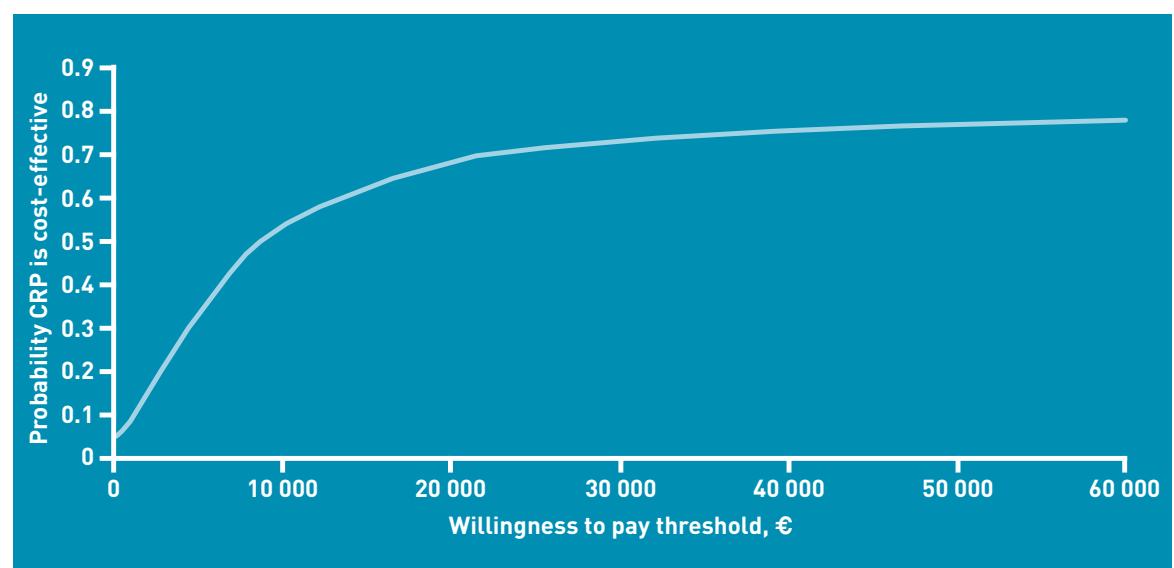

Figure 2. Cost-effectiveness acceptability curve. $C R P=C$-reactive protein. account for differences in outcomes due to cofactors. There is a possibility that not all cofactors are controlled for, and that there may still be a difference between the patient characteristics in the two groups as a result of this residual confounding. To minimise this possibility all relevant cofactors 126 variables) were included. In keeping with the study's pragmatic aim of assessing usual care, clinicians were not directed how they should interpret POCCRP results; instead they were interpreted according to their usual practice. An article ${ }^{7}$ also using data from the GRACE observational study found for Sweden and Norway a CRP value $<20 \mathrm{mg} / \mathrm{L}$ in $65 \%$ of those tested, with antibiotics being prescribed to 19\% these. Among the $13 \%$ with a CRP value $\geq 50 \mathrm{mg} / \mathrm{L}$, $88 \%$ were prescribed antibiotics, indicating that CRP level did influence prescribing

However, the strength of an observational study such as this is that it takes place under conditions that more closely approximate usual care; the findings are therefore likely to have greater applicability to primary care in 'the real world' than findings of experimental studies where use of POCCRP is carefully prescribed and delivered according to patient randomisation. This wider applicability is of particular importance when considering cost-effectiveness, where experimental studies sometimes bear little resemblance to provision in the actual health economy. A further strength is that the study shows what types of patients actually receive a POCCRP test in clinical practice, which is not revealed in randomised studies ${ }^{24}$ and which is relevant to resource allocation decisions. However, the study was limited to 4 weeks of follow-up. While not a problem for the analysis, any long-term issues such as change in practice over time associated with the use of POCCRP would not be detected.

\section{Comparison with existing literature}

Two studies have evaluated the costeffectiveness of POCCRP in a trial setting.., 25 In both cases, POCCRP was cost-effective. The finding that POCCRP testing reduces the rate of antibiotic prescribing for LRTI in primary care is consistent with conclusions in a randomised study carried out in the Netherlands, ${ }^{6}$ which also concluded that POCCRP does not have any significant effect on outcomes, again consistent with the results found here.

\section{Implications for research and practice}

The results from this study provide useful information to decision makers. In the short term, they suggest that POCCRP has no adverse influence on the health of patients, 
and may be associated with a reduction in the probability of prescribing, which would ultimately lead to societal health benefits in the long-run through helping to contain antibiotic resistance. The incremental cost of POCCRP testing per unit reduction in antibiotic prescribing is $€ 112.70$, and the incremental cost per QALY gained is $€ 9391$. However, there is no commonly accepted threshold at which achieving a particular quantum of antibiotic prescribing would be considered cost-effective. To determine whether POCCRP is a good use of healthcare resources, the societal benefit of reduced antibiotic use needs to be considered. ${ }^{26}$ Such benefit stems from its potential to contain antimicrobial resistance. ${ }^{27-30}$ Antibiotic resistance is generally low in Nordic countries in comparison to other parts of Europe..$^{31}$ Prescribing in the Nordic countries is also lower than in most other parts of Europe. This could be partly as a result of high use of POCCRP tests in the Nordic countries. Other European countries could also see benefits from implementing POCCRP testing in primary care. However, to estimate the long-term effect of reduced antibiotic use on antibiotic resistance and the associated societal benefit, mathematical models of bacterial infection are required. Early models have produced interesting theoretical results, ${ }^{32}$ but studies such as this one are needed to parameterise them so that they can be used for policy making.

Although this article provides evidence of cost-effectiveness, there are also resource implications from widespread use of the test. It is difficult to predict the total size of these costs, although the relatively small cost of the test needs to be balanced against potential longer-term costs associated with increased resistance.

\section{Funding}

This study was funded as part of the GRACE (Genomics to combat resistance against antibiotics in community-acquired LRTI in Europe), a European Commission funded project within the Sixth Framework Programme, reference number LSHMCT-2005-518226.

\section{Ethical approval}

This study was approved by the ethics review committees in all participating countries and written consent was obtained from all participants before their inclusion into the study.

\section{Provenance}

Freely submitted; externally peer reviewed.

\section{Competing interests}

The authors have declared no competing interests.

\section{Acknowledgements}

We thank the GRACE Clinical Platform, Mark Kelly and Samuel Coenen for their input into this study.

\section{Discuss this article}

Contribute and read comments about this article on the Discussion Forum: 


\section{REFERENCES}

1. Metlay JP, Kapoor WN, Fine MJ. Does this patient have community-acquired pneumonia? Diagnosing pneumonia by history and physical examination. JAMA 278(17): 1440-1445.

2. van der Meer V, Neven AK, Van den Broek PJ, Assendelft WJJ. Diagnostic value of $C$ reactive protein in infections of the lower respiratory tract: systematic review. BMJ 2005; 331(7507): 26

3. Graffelman AW, Le Cessie S, Knuistingh NA, et al. Can history and exam alone reliably predict pneumonia? J Fam Pract 2007; 56(6): 465-470.

4. Cals JWL, Hopstaken RM, Butler CC, et al. Improving management of patients with acute cough by $\mathrm{C}$-reactive protein point of care testing and communication training (IMPAC 3 T): study protocol of a cluster randomised controlled trial. BMC Fam Pract 2007; 8: 15

5. Ip M, Rainer TH, Lee N, et al. Value of serum procalcitonin, neopterin, and C-reactive protein in differentiating bacterial from viral etiologies in patients presenting with lower respiratory tract infections. Diagn Microbiol Infect Dis 2007; 59(2): 131-136.

6. Cals JWL, Butler CC, Hopstaken RM, et al. Effect of point of care testing for C reactive protein and training in communication skills on antibiotic use in lower respiratory tract infections: cluster randomised trial. BMJ 2009; 338: b1374.

7. Jakobsen KA, Melby H, Kelly MJ, et al. Influence of CRP testing and chest findings on antibiotic prescribing in adults presenting with acute cough in primary care. Scand J Prim Health Care 2010; 28(4): 229-236.

8. Hansson LO, Carlsson I, Hansson E, et al. Measurement of C-reactive protein and the erythrocyte sedimentation rate in general practice. Scand J Prim Health Care 1995; 13(1): 39-45.

9. Dahler-Eriksen BS, Lauritzen T, Lassen JF, et al. Near-patient test for C-reactive protein in general practice: assessment of clinical, organizational, and economic outcomes. Clin Chem 1999; 45(4): 478-485.

10. Flanders SA, Stein J, Shochat G, et al. Performance of a bedside C-reactive protein test in the diagnosis of community-acquired pneumonia in adults with acute cough. Am J Med 2004; 116(8): 529-535.

11. Weis N, Almdal T. C-reactive protein - can it be used as a marker of infection in patients with exacerbation of chronic obstructive pulmonary disease? Eur J Intern Med 2006; 17(2): 88-91.

12. Galetto-Lacour A, Zamora SA, Gervaix A. Bedside procalcitonin and C-reactive protein tests in children with fever without localizing signs of infection seen in a referral center. Pediatrics 2003; 112(5): 1054-1060.

13. Kohli V, Singhi S, Sharma P, Ganguly NK. Ann Trop Paediatr 1993; 13(4): 373378.

14. Diederichsen $\mathrm{HZ}$, Skamling M, Diederichsen A, et al. Randomised controlled trial of CRP rapid test as a guide to treatment of respiratory infections in general practice. Scand J Prim Health Care 2000; 18(1): 39-43.

15. Butler CC, Hood K, Verheij T, et al. Variation in antibiotic prescribing and its impact on recovery in patients with acute cough in primary care: prospective study in 13 countries. BMJ 2009; 338: b2242.
16. Oppong R, Coast J, Hood K, et al. Resource use and costs of treating acute cough/lower respiratory tract infections in 13 European countries: results and challenges. Eur J Health Econ 2011; 12(4): 319-329.

17. Drummond MF, Sculpher MJ, Torrance GW, et al. Methods for the economic evaluation of health care programmes. 3rd edn. Oxford: Oxford University Press, 2005.

18. Greiner W, Weijnen T, Nieuwenhuizen M, et al. A single European currency for EQ-5D health states. Eur J Health Econ 2003; 4(3): 222-231.

19. Watson L, Little P, Moore M, et al. Validation study of a diary for use in acute lower respiratory tract infection. Fam Pract 2001; 18(5): 553-554.

20. Rawlings M, Barnett D, Stevens A. Pharmacoeconomics: NICE's approach to decision-making. Br J Clin Pharmacol 2010; 70(3): 346-349.

21. Hoch JS, Rockx MA, Krahn AD. Using the net benefit regression framework to construct cost-effectiveness acceptability curves: an example using data from a trial of external loop recorders versus Holter monitoring for ambulatory monitoring of 'community acquired' syncope. BMC Health Serv Res 2006; 6: 68

22. Hoch JS, Briggs AH, Willan AR. Something old, something new, something borrowed, something blue: a framework for the marriage of health econometrics and cost-effectiveness and cost-effectiveness analysis. Health Econ 2002; 11(5): 415-430.

23. Briggs $\mathrm{AH}$, O'Brien BJ. The death of cost-minimization analysis? Health Econ 2001; 10(2): 179-184

24. McKee M, Britton A, Black N, et al. Methods in health services research: interpreting the evidence: choosing between randomised and non-randomised studies. BMJ 1999; 319(7205): 312-315.

25. Cals JW, Ament AJ, Hood K, et al. C-reactive protein point of care testing and physician communication skills training for lower respiratory tract infections in general practice: economic evaluation of a cluster randomized trial. J Eval Clin Pract 2011; 17(6): 1059-1069.

26. Coast J, Smith RD, Millar MR. Superbugs: should antimicrobial resistance be included as a cost in economic evaluation? Health Econ 1996; 5(3): 217-226.

27. Coast J, Smith RD. Solving the problem of antimicrobial resistance: is a global approach necessary? Drug Discov Today 2003; 8(1): 1-2

28. Christ-Crain M, Jaccard-Stolz D, Bingisser R, et al. Effect of procalcitonin-guided treatment on antibiotic use and outcome in lower respiratory tract infections: cluster-randomised, single-blinded intervention trial. Lancet 2004; 363(9409): 600-607.

29. Ball P, Baquero F, Cars O, et al. Antibiotic therapy of community respiratory tract infections: strategies for optimal outcomes and minimized resistance emergence. J Antimicrob Chemother 2002; 49(1): 31-40.

30. Goossens H, Guillemot D, Ferech M, et al. National campaigns to improve antibiotic use. Eur J Clin Pharmacol 2006; 62(5): 373-379.

31. Voss A, Milatovic D, Wallrauch-Schwarz C, et al. Methicillin-resistant Staphylococcus aureus in Europe. Eur J Clin Microbiol Infect Dis 1994; 13(1): $50-55$.

32. Laxminarayan R, Brown GM. Economics of antibiotic resistance: a theory of optimal use. J Environ Econ Manage 2001; 42(2): 183-206. 